\title{
A MODEL OF THE INNOVATIVE PURPOSE FOR RESPONSIBLE INNOVATION: TOWARDS DESIGN-BASED CORPORATE GOVERNANCE
}

\author{
J. Lévêque ${ }^{\otimes}$, K. Levillain and B. Segrestin \\ Mines ParisTech, France \\ $\triangle$ jeremy.leveque@mines-paristech.fr
}

\begin{abstract}
Evolutions in corporate law recently introduced an optional commitment mechanism in the corporate contract: a purpose. Its writing is a pivotal but is yet puzzling from a design perspective. Especially it raises questions about how that could help shaping a responsible governance model for innovation. Our paper builds on an extended-decision framework to propose a formal model of how a statedpurpose shapes the decision situation. Our results highlight several purpose formulation strategies and finally a typology regarding how robustness to changes is embedded in the process is proposed.
\end{abstract}

Keywords: purpose, responsible governance, social responsibility, decision making, design theory

\section{Introduction}

\subsection{The issue of responsible innovation}

Corporate attention to responsibility and sustainability is becoming a major preoccupation at the international level in the face of the urging social and environmental challenges of our time. There is a large consensus in management research over the fact that the innovation capabilities of companies should be used as a significant leeway to meet these challenges (eg Scherer and Voegtlin, 2018). However, research in engineering design questions the actual capacity of designers and engineers to take into account these responsibility issues in their reasoning and processes ( $\mathrm{Hu}$ and Cardin, 2015; Winkelman, 2013), highlighting the difficulty to deal with contradictory demands from management and governance levels (Schulte and Hallstedt, 2017), and resulting in diminished feeling of responsibility (Coutts et al., 2017) or the risk of a "dark side" of innovation (Gravier and Swartz, 2009).

Research on corporate social responsibility indeed tends to demonstrate that it is still the dominant view that sustainability is conditional on economic return and not conversely, i.e. that social performance is justified only when it comes with profitability (Levillain et al., 2019; Sandberg, 2011). In practice, this "trade-off" between social (or environmental) and economic outcomes, which has to be optimized by executives and frequently reassessed in turbulent environments where customer expectations rapidly change (Karnani, 2011; Husted and de Jesus Salazar, 2006), is creating contradictory expectations for engineering teams, as the recent examples of the Dieselgate at Volkswagen and the 737 MAX tragedies at Boeing illustrate. While some projects might conveniently improve both performance dimensions, most of strategic decisions are expected to imply favouring one at the expense of the other. As such, the 
quest for responsible innovations resemble the classical dilemmas of decision theory where choices must be made between necessarily suboptimal alternatives (cf. Le Masson et al., 2019).

\subsection{A corporate governance mechanism for responsible innovation}

In this paper, we postulate that responsible innovation precisely means to overcome this "trade-off". The lens of design theory indeed enables to think of this issue another way: instead of considering that the set of alternatives is fixed, the goal is to frame the appropriate design of new possible executives' decisions which would make economic and social dimensions potentially compatible, but at the cost of being partly unknown (e.g. Hatchuel and Weil, 2009). Faced with this unknown, however, fostering a consistently responsible behaviour on the part of companies requires building a framework where "responsible" actions are favoured whatever the decision situations that might occur, thus encouraging decision-makers to potentially design alternative choices when faced with problematic issues (Le Masson et al., 2019) or dilemmas raised by a complex and ever shifting environment.

This mechanism, relying on a commitment of top managerial teams, can be built at the corporate governance level. We argue that It is precisely the goal of legal innovations recently introduced by several countries (US, Italy, France) in the form of new legal forms of corporations, called "Profit-with-Purpose Corporations" (Levillain et al., 2019; Levillain and Segrestin, 2019; Prior et al., 2014). These corporate forms require that a social and/or environmental "purpose" be written in their bylaws, i.e. in the corporate contract. Supported by socially innovative entrepreneurs who specifically wanted to protect their innovation capacity against the uncontrolled search for profitability at the expense of companies' responsible behaviour, these new corporate forms make of this "purpose" a true legal feature, a commitment with teeth, which should therefore not be taken as a simple communication or marketing exercise, as "mission statements" might sometimes have been in the past (Hiller, 2013; Mac Cormac and Haney, 2012). Through this legal innovation, an increasing number of entrepreneurs and CEOs are able to commit themselves to only develop responsible or sustainable innovations, and even concretely to contribute to current social and environmental challenges through designing appropriate new products and services.

\subsection{Research issue: building generative and responsible common purposes}

In all countries where this type of corporate structures has been adopted, a relatively low level of prescription is provided as to how the corporate purpose is to be drafted in the bylaws. Then, if we adopt a design perspective and encourage a design approach of responsibility dilemmas, how should the purpose be formulated?

From a design theory viewpoint, the concept of corporate purpose is indeed puzzling: on the one hand, it is well known that as innovative design implies manipulating concepts that designate still partly unknown objects, a well-identified approach for securing the cooperation in the unknown of various participants (persons or organizations) to the design process requires the definition of "common purposes" (Gillier et al., 2012; Levillain et al., 2014) or "common unknowns" (Berthet et al., 2016; Kokshagina et al., 2012), i.e. minimal set of values or properties of the design processes for which the different people in the collective agree to invest time and resources despite the unknown nature of the results of the design process (Hooge and Dalmasso, 2015).

On the other hand, if the formulation of the corporate purpose is supposed to be long-lasting (as it is written in the company's bylaws), while effectively controlling what future activities of the firm are acceptable or not, how to make sure that this formulation will not restrict the potential field of action of the company, and therefore cut down future innovation opportunities and be in direct contradiction with the intent to foster innovative design? And if this purpose is supposed to preserve a part of "unknownness" (Hatchuel and Weil, 2009), how to define a common unknown for a "common" that encompasses something as broad and fuzzy as the corporate responsibility towards the society as a whole?

\subsection{Contributions}

In this article, we intend to advance toward to the ongoing discussion on the contributions of engineering design and design theory to management and governance issues (Isaksson et al., 2019) by developing a design theory-based model of such corporate purpose as a governance mechanism which can foster 
sustainable and responsible innovation at the top strategic levels of companies. More specifically, we build on the recent extension of Wald's decision theory to the design of new decisions (Le Masson et al., 2019) to model the purpose as a means to frame future decision situations of top executives in such a way that responsible choice alternative be designed when facing a problematic trade-off.

Faced with numerous attempts of companies to formulate this purpose with tremendous difficulty (both in the US and in France), we intend to offer both a theoretical model that advances knowledge on the corporate governance of innovation, and a practical method to help policy-makers and entrepreneurs making the most of these new legal statutes.

Our results contribute on a better understanding regarding formulation strategies that would meet the purpose-targeted responsibilities objectives. The learning objectives necessary to maintain a lasting commitment when faced with future undesirable situations in the unknown are specified. And finally, a typology of purposes formulation strategies regarding how robustness to change and to unknown is embedded in the process is drawn.

\section{Beyond "contracting in the unknown": substantive generative purposes}

\subsection{Contracting in the unknown}

Faced with the challenge of designing governance mechanisms that are able to deal with the recent transformation of innovation regimes towards intensive innovation, previous research has already considered inventing contracts which aim at dealing with the unknown created by innovative collective action. Alvarez and Barney (2005) highlight that most governance systems cannot ensure optimal distribution of decision rights in radically uncertain contexts because none of the participants to the collective action is supposed to have enough knowledge to make the appropriate choices despite the unknown.

Grounded in the "incomplete contract" approach of economic theories of the firm (e.g. Hart and Moore, 1990), the "contracting in the unknown" approach (Grandori and Furlotti, 2019) therefore suggests that the contracts (should) be "associational" and "procedural", meaning that their aim is not to predict the future activities, but to secure the initial investment of participants, and to distribute decisions rights to the pro rata of these investments. This way, when alternative states of nature (Wald, 1950) are "discovered" along the collective action, there is no ambiguity as to how decisions must me made (or rather who must make decisions) to deal with novel situations (Grandori, 2013; Grandori and Furlotti, 2019). This model is also quite close to the previous "commitment in the unknown" models pertaining to exploratory partnerships (e.g. Segrestin, 2005; Gillier and Piat, 2008) in which the means of collective action must be secured despite the unknown nature of the outcomes. While the latter agreed on the need to secure initial investments, they also called for vigilance on how to revise the objectives and means in a stepwise process, in the light of what had been learned during the partnership.

\subsection{From "procedural" to "substantive" mechanisms}

In the previous models, the unknown nature of future decision situations is not paralyzing collective action and does not constrain the writing of formal agreements between participants. However, can such models secure the responsible character of the decisions that will be made? The traditional view is that such responsibility will be achieved if the decision rights are properly distributed among the participants that will be affected by the decision made. This assumption can be considered the formal basis to stakeholder theory whereby properly balanced governance will ensure appropriate decisions. Two formal limitations at least, however, can be stressed within this model: first, "responsibility" is mechanically restricted to what participants having a voice in the governance system can demand; and second, in most cases the compromise that is necessary to deal with contradictory interests in a decision situation is ultimately decided by a single decision-maker. The first condition entails a difficulty to represent "silent" stakeholders such as the environment or future generations, and to consider the fact that the list of stakeholders might not be bounded (and known ex ante) as soon as innovative action creates initially unknown impacts or opportunities. The second condition breaches the ideal distribution of decision rights. 
This is where the new "Profit-with-Purpose" corporate forms create a strong difference with previous approaches in corporate governance. By requiring shareholders and directors to engage on a purpose, explicitly linked to social and/or environmental issues, they cannot only rely on the engagement of initial investments, or on the means to be assigned to a collective project. Formally, this change is very close to reverting back from "procedural rationality" to "substantive" rationality in the words of Simon (1976), as the content of the purpose is not reduced to the process under which a decision can be judged as rightly made, but contains the effective goals and constraints on collective action that makes is acceptable or not.

In doing so, the hope of the lawyers drafting the corporate forms was to create a kind of "lock" which would prevent either shareholders from demanding of all companies' projects to be designed for profit-maximization only, or managers from using the fuzziness of existing engagements to do greenwashing, i.e. pretending to work for positive social and environmental impact for brand value while changing nothing in the business-as-usual strategy.

\subsection{Responsible or generative common purposes?}

However, how to ensure that this "lock" is not stifling innovation rather than fostering it? At first glance, such a mechanism could easily be used as a simple assessment tool, filtering potential innovative projects through their probability to meet the requirements written in the bylaws. If so, the new governance mechanism would appear as a simple decision-making tool, without any new knowledge gained to develop new potential alternatives. Such a reading, assuredly widespread among entrepreneurs only looking for a legal version of traditional impact measurement tools, would not promote the development of sustainable or responsible innovation.

How, then, is it possible to use such a legal purpose as a kind of "governance-aided" responsible design? This lead would make this purpose closer to the notion of "common unknown" (Berthet et al., 2016; Kokshagina et al., 2012; Le Masson and Weil, 2014), i.e. a set of properties guiding the collective design process with the following properties:

- Identifying a question or a concept that highlights knowledge gaps of some potential value for the actors involved in the design process (even if for different reasons);

- Minimizing the cost of future design by some of these actors of objects based on this knowledge development or creation;

- And preserving the generative potential through non-determinism (Le Masson et al., 2012), i.e. not predetermining the set of potential designs through these initial properties.

While this notion has been used in situations in which the collective of participants to the common design process was relatively well-defined at the beginning (i.e. groups of people or organizations (Agogué, 2013; Berthet et al., 2016), colleges of the unknown (Le Masson et al., 2012), etc.), here the "purpose" of profit-with-purpose corporate forms is addressing a much broader population. It is indeed not intended as being a commitment of internal stakeholders participating to value creation processes, but a commitment of the corporation itself towards internal and external stakeholders potentially affected by the definition of a responsible purpose for the company. More specifically, the formulation of the firm's purpose is intended to express the way the company is supposed to carry out "responsible" activities (in the sense of the "corporate social responsibility"). To this end, the "common" of "common unknown" is therefore not designating only people involved in the design process (to secure their investment) but a potentially undefined larger group of people who would be legitimate to have a say on the responsible or sustainable character of the company's activity. Moreover, this commitment is supposed to be long-lasting, as it is incorporated into the company's bylaws which are supposed to be rather stable contracts. It is this tension between long-lasting but illdefined "responsibility" and the aim for non-determinism that we explore in this paper.

In practice, for this governance system to be efficient, i.e. effectively proscribing "irresponsible" innovations while not systematically fostering unprofitable projects, the writing of the actual purpose is therefore of pivotal importance: being written in the corporate contract, it is akin to a design brief which will steer the design of the firm's strategy as well as the criteria for its assessment. It is therefore crucial that this formulation makes explicit the constraints that would rule out what would be 
considered as "irresponsible" innovations but does not impede the capacity of the company to innovate, i.e. upholding a form of generativity.

\subsection{Common pitfalls of current formulations: anchor in the past and fuzzy commitment}

Companies in the US, Italy and France that have already tried to formulate such a "purpose" in their bylaws have naturally encountered strong difficulties to deal with both the objectives of creating a substantive commitment and preserving the non-determinism that is required for generativity.

Through our own inventory of current formulations, encompassing more than 40 cases, we observe two main recurring patterns which exemplify this difficulty:

- Anchor in the past: the first well-identified strategy is to write in the purpose the description of the current activities of the company. For instance, an investment company writing: "we commit to contribute to the current environmental challenge through funding companies involved in environmental innovations". This choice is limiting the legal risks incurred by the commitment because it is easy for the company to prove that they have been carrying out the said activities. However, it is purely deterministic as it only describes already known processes and does not aim at developing new knowledge to carry out more efficient activities in the future for the same general purpose.

- Fuzzy commitment: the second well-identified strategy is to write the purpose as a very fuzzy and distant objective, which is difficult to interpret as a precise commitment. For instance, a company writing: "we act every day in the interest of our customers and the society". Although non-deterministic, this version does not help any design process by not specifying the design space to be explored by the collective. As the interpretation of the purpose's meaning is left to the reader, it might either level out any commitment, or instead be considered as a very broad and engaging formulation, for which significant advance must be shown.

Overall, the writing of an efficient purpose is therefore a difficult task, particularly because there exists no specific model that would help executives understand the underlying mechanisms incurred by such a writing. In the following section, we therefore propose a simple model to represent and design appropriate formulations of purposes for governance-aided design in profit-with-purpose corporations.

\section{A generative model for designing commitment to a corporate purpose: designing the "responsible"}

We have seen that writing of the actual purpose is therefore of pivotal importance it is akin to a design brief which will steer the design of the firm's strategy as well as the criteria for its assessment. It is therefore crucial that this formulation makes explicit the constraints that would rule out what would be considered as "irresponsible" innovations but does not impede the capacity of the company to innovate, i.e. upholding a form of generativity. as an object of governance, the writing of the purpose must serve as a framing tool for decision making. In this respect, the challenge is to ensure that it has the right features, to enable it to provide the decision-maker, whoever he may be, with the resources to anticipate the decisions that will have to be taken for the future of the company.

In the outline of the following model, a formal representation of decision situation will be carried out using Wald's analytical framework under uncertainty (Wald, 1950) and then within an extended generative perspective (Le Masson et al., 2019). I will help to understand how purpose can play a role in these decision-making processes by modelling how a that leads to the design and the subsequent action on decision-making situations.

As noted earlier, the literature has pointed out some sort of specifications in respect of the matter of what could be a well-built purpose, meaning it should to consistently "improve" decision-making situations, whatever the decision maker(s). We specify these results under the following pair: 
1. the ability to be long lastingly committed to the purpose and thus resisting to variations of context. In other world it would mean preventing "irresponsible" decisions.

2. the ability to produce design proposals that are different from existing solutions and design standards: therefore, formulating a purpose which is not deterministic and foster the proposals of new alternatives;

In addition, the legal nature of the purpose, through its registration in the bylaws, is also to be modelled.

\subsection{Building the reference frame of eligible decisions: a model of purpose}

We first resume the model from an analytical perspective using the Bayesian formalism of Wald's frame-work. We show how does it contribute to the construction of a certain type of decision-making situation.

In the Wald's decision model under uncertainty, actors are conducting decisions that are based on a given set of alternatives $D$, actions that they can take, and a given set of events $\Theta$, about which they have a priori beliefs $\mu$. The decision-maker(s) navigate through the accessible paths according to expected losses (or utilities) that are assumed with a cost-function $C$ and aim at making the better decision, that is to say the one which minimize their costs (or maximize their utility).

Regarding to this model, claiming the pursuit of actions related to a purpose suppose that the decision space for each future decision made by executives will be altered in a way that decisions favouring the stated purpose will generally (or systematically, depending on the strength of the legal commitment) prevail. We therefore suggest modelling the purpose in the following way:

a) First, by integration to the cost function $C^{\prime}$ new criteria that will make unbearable to the decision-maker to make decisions leading to $\left(d_{i}, \theta_{\mathrm{i}}\right)$ couples that are deemed contradictory to the purpose, i.e. "irresponsible";

b) Then, the extension or reframing of the space of events to new events $\theta^{\prime}$ irelated to the objects designated by the purpose. Formally, adding this new state of nature, complexify the decision situation. Let's consider $\theta_{\text {I }}^{\prime}$ considered desirable as stated, especially if $\neg \theta^{\prime}{ }_{\mathrm{i}}$ occurs, it stands for a new risk for the purpose, as it can shift the decision preferences, i.e.

$$
\forall i \exists \theta^{\prime}, \mathrm{C}\left(d_{1}, \theta_{i}\right)<\mathrm{C}\left(d_{2}, \theta_{i}\right) \rightarrow \mathrm{C}\left(d_{1}, \neg \theta^{\prime} \theta_{i}\right)>C\left(d_{2}, \neg \theta^{\prime} \theta_{i}\right)
$$

Formally, this transcribe the operativeness of the purpose. We define operativeness as the ability to have a substantive influence on the decision situation, both meaning (a) by increasing the desirability of decision $d_{i}$ which contribute to the advance of the purpose (through $\mathrm{C} \rightarrow \mathrm{C}^{\prime}$ ) and (b) by identifying new risks that could lead to inappropriate decisions in regard to the interests stated in the purpose $\left(\Theta \rightarrow \Theta^{\prime}\right)$.

So described, the mission serves as a regulatory function of actual decisions in a restructured decision-making space. This development allows us to establish the characteristics of a purpose, which is basically the formalization of a decision guide that is expressed in a decision-making space on which bad been identified a fixed-set of desirable events. So, described, the purpose meets the prerequisites since 1) it protects against today's irresponsible decisions and 2) it builds a coherent decision situation regarding understanding of the world $\left(\theta_{\mathrm{i}}\right.$ and their beliefs $\left.\mu\right)$ and the desired stated-purpose (Figure 1).

\subsection{Overcoming the governance issue: purpose versus unknown}

At this stage, the model of decision-related purpose into action is not yet totally satisfactory because it does not transcribe the consequences on the future of the legal commitment induced by a formal registration in the bylaws. This legal commitment can be considered as a prevention mechanism of potential risks of drifting away from the purpose. In terms of decision that means for the decisionmaking situation to be somehow robust to the evolution of the decision space.

However, the latest developments in innovation management and extended decision theory (Loch et al., 2011) inform us that this structuration of a decision-making framework is not completely satisfactory since Wald's model has proven its limitations regarding two aspects: 
- first, it is therefore impossible to a priori predict all the states of nature, especially those that are undesirable, at the beginning when the situation decision is set. Yet, decision situation can be subject to changes - for instance when uncovering new state of the nature $\theta^{*}$ - then the beliefs and costs associated a with each of the states of nature can dramatically change. How to carry out a decision regarding a newly uncovered state of nature which can potentially affects my cost function?

- and then, there is no guarantee that in any situation a desirable decision with respect to the purpose among the set $\mathrm{D}$ can always be find: that means either none of the $\mathrm{C}\left(\mathrm{d}_{\mathrm{i}}\right)$ reaches a threshold value or $\mathrm{D}$ does not allow to solve competing demands or trade-offs.

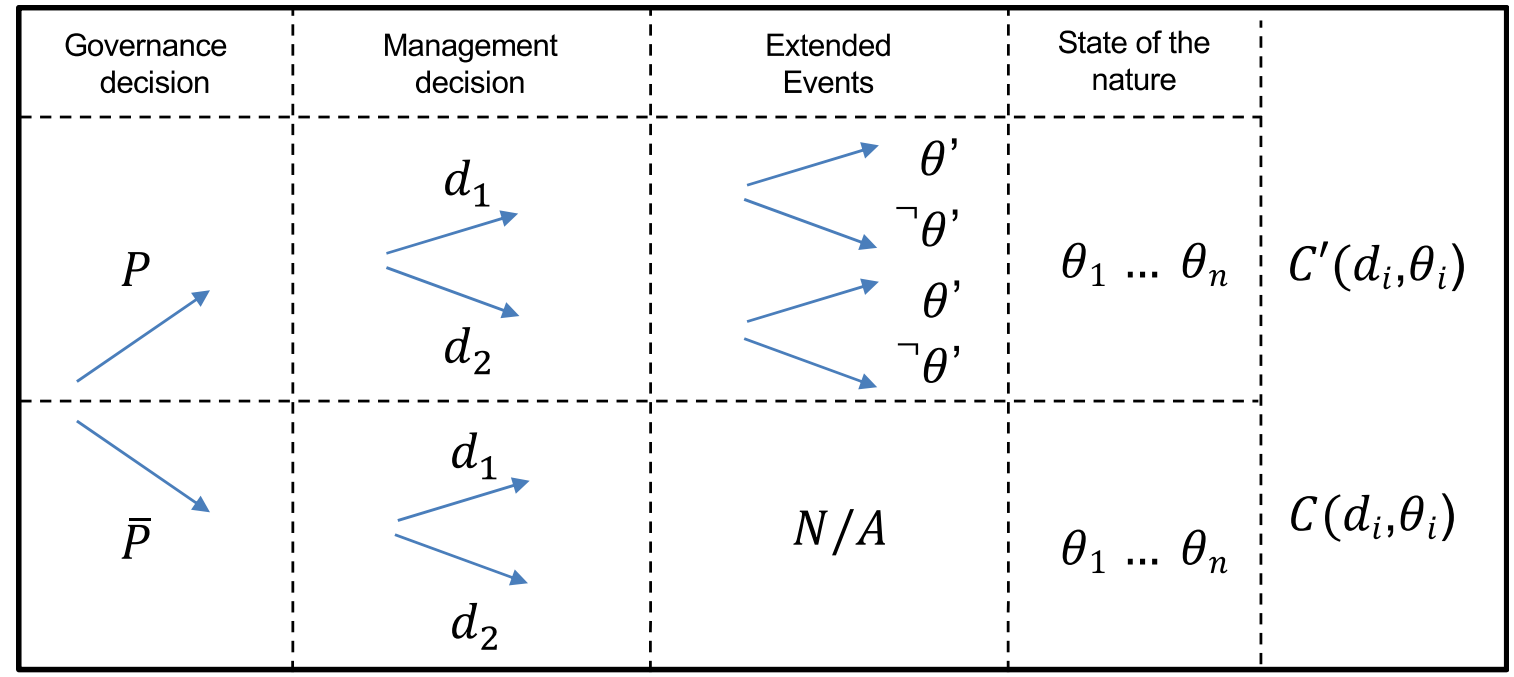

Figure 1. Simplified representation of a Bayesian network of a decision situation, integrating a legally-stated purpose (P)

Therefore, to be robust to these possible developments, the purpose-related decision-making situation must be resilient to this type of inflection, and offer the decision-maker the ability to apprehend evolutions and to maintain or design alternative responsible decisions. It highlights two key challenges associated with the construction of a purpose. Even if the objective regarding the decision situation is to avoid having to design all possible futures (in terms of alternatives and actions) in order to write a "complete contract" (Grandori and Furlotti, 2019), it seems however necessary to develop capacities to deal with this unknown, meaning:

- potentially requires to extend the decision set, from $\mathrm{D}$ to $\mathrm{D}^{*}$ to overcome the blocking situations and learns about futures undesirables' decisions;

- finding a way to cope with future undesirable states of the nature $\theta^{*}$.

Besides, the work on uncertainty reduction, which has largely occupied decision theorists ( $\{$ Citation $\}$ ), on a design perspective, Le Masson et al. (2019) have been able to demonstrate the existence of a possible extension of the decision-making situation, using design theories. This theoretical intuition was then confirmed and tested in operational decision-making situations in the world of aeronautical equipment (see Le Glatin, 2018). Le Masson et al. indeed showed on the historical example of Wald (1950) that it is possible to design a better decision-making situation. Either by working on D and extending it to $\mathrm{D}^{*}$ (i.e. designing a better alternative action plan, by either designing a better decision known in the current state of belief or a better decision independently of any state of nature). Or it is possible to design or uncover new states of natures in the decision situation, which provides a decision-making ability facing this unknown.

Back to our model then, far from freezing a representation of the decision-making situation and its desirable outcomes, the purpose $\left(C^{\prime}, D^{*}, \Theta^{*}\right)$ can also entails a reactive dimension, recognizing the possibility for governance to have to face with unforeseeable events. The purpose taken as a commitment that show a form of permanency, despite the possibility of unknown elements 
occurring, presupposes then a learning (which is the L function in Wald's framework) on the decision-making situation that encompass these perspectives. In a design-based, the L function at least integrate:

a) a learning in the events space $\theta^{*}$ through its vulnerabilities: designing futures possible undesirable and their factors and ii) assess how to maintain currents commitment by offsetting the costs associated by any evolutions in $\theta^{*}$, i.e.:

$\left.\forall \mathrm{i}, \mathrm{C}^{\prime}(\mathrm{di},\urcorner \theta^{*} \theta_{i}\right)=\mathrm{C}^{\prime}\left(d_{1}, \theta^{*} \theta_{i}\right)$

b) a learning in the alternatives space $D^{*}$ : fostering the development of new alternatives $d^{*}$ that can seek to i) be better than every known decision in the current belief, ii) avoid or precise the drivers of undesirable decisions or iii) generic decisions which make it possible to avoid dependence on beliefs; i.e.:

$\exists d^{\prime}, C^{\prime}\left(d^{\prime}, \theta^{*} \theta_{i}\right)>C^{\prime}\left(d_{1,2}, \neg \theta^{*} \theta_{i}\right)$

To conclude, the canonical model, presented in the previous section (See 3.1.1), which we rename protective purpose, seems promising in relation to the governance issues considered because it organizes a stabilized representation of a desirable world and provides a decisionmaking latitude that leaves room for innovation and frees the decision-maker from non-purpose related influences.

If this approach seems robust with regards to the identified threats, it nevertheless appears sensitive considering the potential occurrence of unknown elements in the decision-making situation. When extending the understanding of purpose into a design theory perspective, the possibility of maintaining a substantive commitment and preserving the non-determinism that is required for generativity while considering the unknown of future decision situation is considered. Theoretically however at least two types behaviour when facing the unknown should be distinguished, depending on whether it seek to react to its happening (reactive purpose) or to define generic rules that make the course of action independent of all or part of future external contingencies (projective purpose).

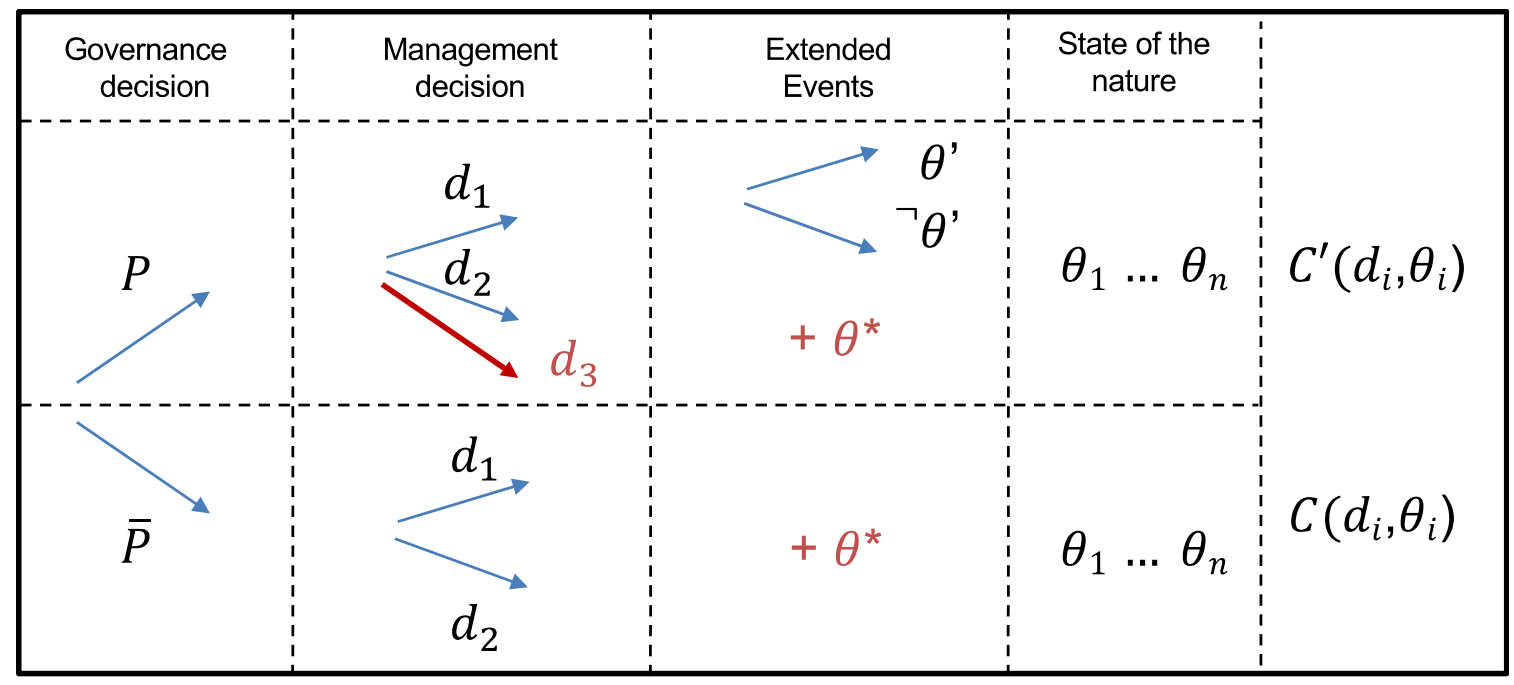

Figure 2. Extension of the state-related purpose with design perspective

\subsection{Reinterpretation of current pitfalls in corporate purpose formulation}

Building on this formal model, it now appears possible to express an assessment on both the quality and robustness of the formulation of a purpose with regard to its decision-making perspective. In particular, we can to go back over the classic pitfalls encountered by companies that have complied with the exercise of formulating their purpose (Table 1). 
Table 1. Reading the current pitfalls through the formal model of corporate purpose

\begin{tabular}{|c|c|c|c|}
\hline & & Anchor in the past & Fuzzy commitment \\
\hline Functions & Examples & $\begin{array}{l}\text { "We commit to contribute to the } \\
\text { grand challenges through funding } \\
\text { companies involved in } \\
\text { environmental innovations" }\end{array}$ & $\begin{array}{l}\text { "We act every day in the interest } \\
\text { of our customers and the society" }\end{array}$ \\
\hline \multirow[t]{2}{*}{$\begin{array}{l}\text { Regulatory } \\
\text { function }\end{array}$} & $\begin{array}{l}\text { Assessment for } \\
\text { current } \\
\text { decisions }\end{array}$ & $\begin{array}{l}\text { Full determinism: Prescribe the } \\
\text { decision which has already been } \\
\text { done and does not consider the } \\
\text { space of events on which the } \\
\text { action is based }\end{array}$ & $\begin{array}{l}\mathrm{C} \text { is unaffected by the purpose } \\
\text { since it is expressed on generic } \\
\text { states of the world. }\end{array}$ \\
\hline & $\begin{array}{l}\text { Protection } \\
\text { against } \\
\text { inappropriate } \\
\text { decisions }\end{array}$ & $\begin{array}{l}\text { Indeterminability } \\
\text { Do not influence decisions based } \\
\text { on } \theta^{\prime}{ }_{i}\end{array}$ & $\begin{array}{l}\text { Too broad to allow the } \\
\text { assessment of couples }\left(\mathrm{d}_{\mathrm{i}}, \theta_{\mathrm{i}}\right) \text { and } \\
\text { thus to guide the decision among } \\
\text { the considered alternatives } \theta_{\mathrm{i}}\end{array}$ \\
\hline \multirow{2}{*}{$\begin{array}{l}\text { Design guide } \\
\text { for the } \\
\text { commitment in } \\
\text { the unknown }\end{array}$} & $\begin{array}{l}\text { Management of } \\
\text { unforeseeable } \\
\text { events } \Theta^{*}\end{array}$ & \multirow{2}{*}{$\begin{array}{l}\text { L only deals with uncertainty } \\
\text { reduction of the actual sets of } \\
\text { events } \Theta \text {, and alternatives D. } \\
\text { Extension and changes in the } \\
\text { situation decision are not } \\
\text { considered }\end{array}$} & $\begin{array}{l}\text { a) Do not protect the commitment, } \\
\text { since the statement can lead to } \\
\text { extremely variable interpretations }\end{array}$ \\
\hline & $\begin{array}{l}\text { Possible } \\
\text { extension of } D^{*}\end{array}$ & & $\begin{array}{l}\text { b) Do not prescribe/impede } \\
\text { directions of expansion }\end{array}$ \\
\hline
\end{tabular}

\section{Conclusion}

This paper contributes to the building a formal model of purpose stated in the corporate that are emerging through new corporate forms worldwide, the profit-with-purpose corporations. By focusing on describing its role and effects as in the decision-making framework, we defined the purpose as a triplet $\left(C^{\prime}, \Theta^{*}, D^{*}\right)$ which instantiate itself both as i) a regulatory function and ii) a design guide for the commitment in the unknown.

We have shown how this form of purpose can be governance-aided mechanism for responsible innovation. In fact, we showed how the purpose can play a role as filter for undesirable futures decisions and decision-making guide, but also as a support for the generation of future events and alternatives.

Exploring and learning about the unknown seems to be an important condition for maintaining robust engagement over time and despite changes in the decision-making context. Then, typology of purposes has been established according to their relationship to the unknown, distinguishing between 3 categories: protective, reactive and projective purpose. Finally, this model lays the foundations for the constitution of purpose formulation strategies method.

\section{References}

Agogué, M. (2013), L'innovation orpheline. Presses des MINES, Paris.

Alvarez, S.A. and Barney, J.B. (2005), "How Do Entrepreneurs Organize Firms Under Conditions of Uncertainty?", Journal of Management, Vol. 31, pp. 776-793. https://doi.org/10.1177/0149206305279486

Berthet, E.T., Segrestin, B. and Hickey, G.M. (2016), "Considering agro-ecosystems as ecological funds for collective design: New perspectives for environmental policy", Environmental science \& policy, Vol. 61, pp. 108-115.

Coutts, E.R. et al. (2017), "Is product design evil?", in: DS 87-1 (ICED 17) Vol 1: Resource Sensitive Design Vancouver, Canada, 21-25.08. 2017. pp. 209-218.

Gillier, T., Kazakci, A.O. and Piat, G. (2012), "The generation of common purpose in innovation partnerships", European Journal of Innovation Management. https://doi.org/10.1108/14601061211243684

Gillier, T. and Piat, G. (2008), "Co-designing broad scope of technology-based applications in an exploratory partnership”, in: DS 48: Proceedings DESIGN 2008, Dubrovnik, Croatia. pp. 927-934.

Grandori, A. (2013), Epistemic Economics and Organization: Forms of Rationality and Governance for a Discovery Oriented Economy, Routledge.

Grandori, A. and Furlotti, M. (2019), "Contracting for the unknown and the logic of innovation", European Management Review, Vol. 16, pp. 413-426. https://doi.org/10.1111/emre.12291 
Gravier, M.J. and Swartz, S.M. (2009), "The dark side of innovation: Exploring obsolescence and supply chain evolution for sustainment-dominated systems", The Journal of High Technology Management Research, Vol. 20, pp. 87-102.

Hart, O. and Moore, J. (1990), "Property Rights and the Nature of the Firm", Journal of political economy, pp. 1119-1158.

Hatchuel, A. and Weil, B. (2009), "CK design theory: an advanced formulation", Research in engineering design, Vol. 19, pp. 181-192.

Hiller, J.S. (2013), "The Benefit Corporation and Corporate Social Responsibility”, Journal of Business Ethics, Vol. 118, pp. 287-301. https://doi.org/10.1007/s10551-012-1580-3

Hooge, S. and Dalmasso, C. (2015), "Breakthrough R\&D stakeholders: The challenges of legitimacy in highly uncertain projects", Project Management Journal, Vol. 46, pp. 54-73.

$\mathrm{Hu}$, J. and Cardin, M.-A. (2015), "Generating flexibility in the design of engineering systems to enable better sustainability and lifecycle performance”, Res Eng Design, Vol. 26, pp. 121-143. https://doi.org/10.1007/ s00163-015-0189-9

Husted, B.W. and De Jesus Salazar, J. (2006), "Taking Friedman Seriously: Maximizing Profits and Social Performance*", Journal of Management Studies, Vol. 43, pp. 75-91. https://doi.org/10.1111/j.14676486.2006.00583.x

Isaksson, O. et al. (2019), Perspectives on Innovation: The Role of Engineering Design.

Karnani, A. (2011), “CSR Stuck in a Logical Trap: A Response to Pietra Rivoli and Sandra Waddock's 'First They Ignore You...': The Time-Context Dynamic and Corporate Responsibility”, California Management Review, Vol. 53, pp. 105-111.

Kokshagina, O. et al. (2012), "Risk management strategies in a highly uncertain environment: Understanding the role of common unknown", Presented at the IPDM, p. 26.

Le Glatin, M. (2018). Innover pour décider: Modéliser et expérimenter l'ambidextrie décisionnelle pour gérer les métabolismes de l'organisation innovante (Doctoral dissertation, Paris Sciences et Lettres).

Le Masson, P. et al. (2019), "Designing Decisions in the Unknown: A Generative Model", European Management Review, Vol. 16, pp. 471-490. https://doi.org/10.1111/emre.12289

Le Masson, P. and Weil, B. (2014), "Réinventer l'entreprise: la gestion collégiale des inconnus communs non appropriables".

Le Masson, P. et al. (2012), "Why are they not locked in waiting games?", Unlocking rules and the ecology of concepts in the semiconductor industry. Technology Analysis \& Strategic Management, Vol. 24, pp. 617-630.

Levillain, K., Agogué, M. and Berthet, E. (2014), "Framing a generative common purpose: a critical skill for social entrepreneurs to achieve social innovations", Presented at the ISPIM Americas.

Levillain, K. and Segrestin, B. (2019), "From primacy to purpose commitment: How emerging profit-with-purpose corporations open new corporate governance avenues", European Management Journal, Vol. 37, pp. 637-647.

Levillain, K., Segrestin, B. and Hatchuel, A. (2019), Profit-with-Purpose Corporations: An Innovation in Corporate Law to Meet Contemporary CSR Challenges, Oxford Handbook of Corporate Social Responsibility. Oxford University Press.

Loch, C.H., DeMeyer, A. and Pich, M. (2011), Managing the unknown: A new approach to managing high uncertainty and risk in projects, John Wiley \& Sons.

Mac Cormac, S. and Haney, H. (2012), "New Corporate Forms: One Viable Solution to Advancing Environmental Sustainability", Journal of Applied Corporate Finance 24.

Prior, C., Cohen, S.R. and Fox, T. (2014), "Profit-with-Purpose Businesses - Subject paper of the Mission Alignment Working Group”, Social Impact Investment Taskforce, G8.

Sandberg, J. (2011), "Socially Responsible Investment and Fiduciary Duty: Putting the Freshfields Report into Perspective", Journal of Business Ethics, Vol. 101, pp. 143-162. https://doi.org/10.1007/s10551-010-0714-8

Scherer, A.G. and Voegtlin, C. (2018), "Corporate Governance for Responsible Innovation: Approaches to Corporate Governance and Their Implications for Sustainable Development. Academy of Management Perspectives".

Schulte, J. and Hallstedt, S. (2017), "Challenges and preconditions to build capabilities for sustainable product design”, in: DS 87-1 ICED 17 Vancouver, Canada, 21-25.08. 2017. pp. 001-010.

Segrestin, B. (2005), "Partnering to explore: The Renault-Nissan Alliance as a forerunner of new cooperative patterns", Research policy, Vol. 34, pp. 657-672.

Simon, H.A. (1976), "From substantive to procedural rationality", in: Kastelein, T.J., Kuipers, S.K., Nijenhuis, W.A., Wagenaar, G.R. (Eds.), 25 Years of Economic Theory. Springer US, Boston, MA, pp. 65-86.

Wald, A. (1950), Statistical decision functions, John Wiley \& Sons, New York.

Winkelman, P.M. (2013), "Sustainability, design and engineering values, in: DS 75-2: Proceedings of the 19th International Conference on Engineering Design (ICED13) ", Design for Harmonies, Vol. 2: Design Theory and Research Methodology, Seoul, Korea, 19-22.08. 2013. 